\title{
Finansiële beleid van 'n handelsonderneming tydens prysstyging
}

\author{
W.D. Hamman \\ Universiteit van Stellenbosch Bestuurskool, Bellville
}

\begin{abstract}
Financial policy of a trading enterprise during inflation The statement that inflation has a negative impact upon cash flow is often heard. The question now arises whether this statement is valid. Are all undertakings affected in a negative way or do some companies benefit? An analysis of a trading concern was performed to find out whether such a concern is hedged against inflation or what its profits should be to hedge itself against inflation for given working capital combinations. The effects of stock profits or no profits and FIFO/LIFO are analyzed. A very important conclusion is drawn that illiquid enterprises do better under these circumstances than the more liquid firms. It appears that illiquidity is a prerequisite for a hedge against inflation if gross margin is small as compared to inflation. However, as and when the ratio profit/inflation improves, the requirement of illiquidity is less critical and can even be dropped.
\end{abstract}

S. Afr. J. Bus. Mgmt 1980, 11: $37-41$

Die stelling word dikwels gemaak dat inflasie kontantvloei nadelig raak. Die vraag ontstaan of die stelling dat inflasie ' $n$ negatiewe uitwerking het op kontantvloeiresultate in alle gevalle of net in sekere gevalle geldig is. Ondersoek is ingestel om vas te stel in watter mate 'n handelsorganisasie verskans is teen inflasie, of anders gestel, wat sy winsgrens behoort te wees om verskans te wees teen inflasie vir gegewe bedryfskapitaalkombinasies. Die gevolge van voorraadwinste al dan nie en die uitwerking van EIEU/LIEU word ondersoek. 'n Belangrike gevolgtrekking is dat illikiede ondernemings beter vaar as die meer likiedes. Terwyl dit waar is dat illikiditeit 'n voorvereiste is vir verskansing teen inflasie as die winsgrens laag is in verhouding met die inflasiekoers, verval hierdie voorvereiste van swak likiditeit sodra die verhouding wins/inflasie hoog raak.

S.-Afr. Tydskr. Bedryfsl. 1980, 11: 37 - 41
Met die koms van jaarlikse dubbelsyfer inflasie word die bewering dikwels gemaak dat inflasie (prysstygings) kontantvloei nadelig beïnvloed. Hierdeur word geïmpliseer dat sodanige uitwerking altyd nadelig is en 'n mens sou seker kan aflei dat sodanige nadelige uitwerking dieselfde gaan wees vir verskillende ondernemings. Dit behoort dus interessant te wees om te let of 'n bepaalde inflasiekoers alle maatskappye ewe nadelig raak (bv. vir 'n konstante winsgrens) en of die resultate ook afhanklik is van die samestelling: bruto winsgrens/balansstaatsamestelling/ inflasiekoers.

Om dit te illustreer, word gebruik gemaak van 'n baie vereenvoudigde model van 'n onderneming wat slegs bedryfskapitaalitems het (d.w.s. geen vaste bates nie). Gestel verder dat:

- aankope $=$ verkope $=100$ eenhede per maand (d.w.s. daar vind geen reële groei plaas nie)

- kosprys per eenheid is $R 1,00$

o verkoopprys per eenheid is $R 1,10$ (d.w.s. 'n brutowinspersentasie van $10 \%$ op kosprys)

- salarisse $=\mathbf{R} 4$ per maand

0 belastingkoers $=\mathbf{4 8 \%}$

- debiteure (D), voorrade (V) en krediteure (K) word in maande (waar elke maand verkope van 100 eenhede het) uitgedruk, bv.

3 maande beteken $3 \times 100$ eenhede

2 maande beteken $2 \times 100$ eenhede

- alle kontant op hande op 31 Desember 1979 word as 'n kontantdividend uitbetaal

o op 1 Januarie 1980 styg slegs die kosprys van $R 1,00$ per eenheid na $R 1,11$ per eenheid

- die bruto-winspersentasie van $10 \%$ word in 1980 gehandhaaf, word as die kosprys $\mathrm{R} 1,11$ is, die verkoopprys $1,11 \times 1,10=1,221$

o sonder die prysstyging op 1 Januarie 1980 sal die wins vir die jaar tot 31 Desember 1980 R37,44 wees.

Inkomstestaat vir die jaar tot 31 Desember 1980

Verkope $12 \times 100 \times 1,10$

$=1320,00$

Koste van verkope $12 \times 100 \times 1,00$

$=\underline{1200,00}$ 120,00

Salarisse $12 \times 4$

48,00

Belasting $\mathbf{4 8 \%}$

Professor, Universiteit van Stellenbosch Bestuurskool, Posbus 1058

Bellville 7534, Suid-Afrika 
In die afwesigheid van inflasie sal die kontant ook toeneem met $R 37,44$, ongeag die bedryfskapitaalkombinasies.

Op 1 Januarie 1980 het bestuur twee onmiddellike alternatiewe:

- ou voorraad (kosprys RI per eenheid) kan nog steeds (solank as wat die ou voorrade hou) verkoop word teen R1, 10; of

- ou voorrade kan onmiddellik verkoop word teen die verkooppryse van die nuwe voorraad, naamlik $1,11 \times 1,10=1,221$.

In die cerste geval praat ons van 'geen voorraadwins', en in die tweede geval is daar sprake van die maak van 'voorraadwins'. Die realisasie van voorraadwins beteken dus niks anders nie as 'n hoër brutowins $(22,1 \%)$ as normaalweg $(10 \%)$.

Terselfdertyd kan voorrade waardeer word op die basis van eerste-in-eerste-uit (EIEU) en laaste-in-eerste-uit (LIEU). In laasgenoemde se geval sal die winste uiteraard daal, maar kontantvloei sal verbeter met 0,48 maal die winsdaling.

Ter verduideliking sal 'n sestal kombinasies van debiteure, voorraad en krediteure gebruik word (uitgedruk in maande). Die resultate na 12 maande, dit wil sê op 31 Desember 1980, word in Tabel 1 gegee. Daar moet onthou word dat indien daar geen inflasie op 1 Januarie 1980 was nie, dan sou die wins en die kontantposisie vir:

- al ses bedryfskapitaalkombinasies

\section{en/of}

- die keuses tussen voorraadwins al dan nie en/of EIEU/LIEU R37,44 gewees het.

Tabel 1 se resultate kan soos volg opgesom word. Weens die feit dat die bruto-winspersentasie op nuwe voorraad gehandhaaf word op $10 \%$ en omdat vaste koste van R4 per maand nie geïnfleer word nie, is alle winste na belasting hoër ongeag of daar voorraadwinste gemaak word of nie, en ongeag of EIEU/LIEU gebruik word (vergelyk kolomme A, C \& E).

Winste toon 'n interessante neiging. Wat kolom $\mathbf{A}$ betref, blyk dit duidelik dat wins ' $n$ funksie is van die hoeveelheid voorraad op hande, hoe meer voorrade hoe hoër is die winste. Kolom E se winste bly konstant ongeag die voorraad op hande, want die inflasiewins op die voorrade word geëlimineer deur LIEU.

Die oomblik wat daar egter na kontant gekyk word, is daar 'n merkwaardige verskil te bespeur. Neem bv. Voorraadwins + EIEU en vergelyk kolomme A en B. Ondernemings 1 tot 4 toon identiese winste van R61,46 dog kontant wissel tussen $R 3,16$ en $R 39,46$. 'n Rowwe aanduiding van likiditeit kan verkry word deur die verhouding $\frac{\mathrm{D}+\mathrm{V}}{\mathrm{K}}$ te neem. Hoe beter die likiditeitsverhouding hoe laer is die kontant, en dit vir 'n konstante winssyfer. In die geval van onderneming 1 met 'n likiditeitsyfer van $\frac{3+3}{1}=6$, is die kontant R3,16 en vir onderneming 4 met 'n likiditeitsyfer $\operatorname{van} \frac{0+3}{1}=3$, is die kontant $R 39,46$.

Hierdie argument kan deurgetrek word tot enige kombinasie van $D, V$ en $K$ en ongeag of daar sprake is van voorraadwins al dan nie, en/of EIEU/LIEU. Baie interessant blyk dit dat 'n likiditeitsyfer van 1 (onderneming 6) dwarsdeur die hoogste kontantvloei het. Onderneming 6 se profiel van kontantverkope (debiteure $=0$ ) en ' $n$ voorraadomset van 12 maal per jaar (voorraad $=1$ maand) en krediteurbetaaltermyn van 30 dae slaan nogal baie op dié van die groot kettingwinkels in Suid-Afrika wie se suksesverhale nie onbekend is nie.

Tabel 1 toon 'n groot alledaagse verskynsel. As die eerste vier ondernemings geneem word, het hulle presies dieselfde winssyfers vir die drie moontlikhede, naamlik:

- voorraadwins + EIEU

- geen voorraadwins + EIEU

- voorraadwins + LIEU.

Neem bv. kolom C; die winste vir die eerste vier ondernemings is almal R42,59 maar die beskikbare kontant verskil heelwat. Die eerste onderneming het 'n oortrokke rekening van $R 15,71$ terwyl nr. 4 R20,59 in die bank het. Beide is uiteraard heelwat laer as die R37,44 wat in die bank sou gewees het as inflasie $=0 \%$ was.

'n Mens sou dus die stelling kon maak dat winste nie juis nadelig geraak is nie (vergelyk kolomme $A, C \& E$ ). Dog blyk kontant die kritiese area te wees. Dit is dus die kontantsy van die onderneming wat nadelig geraak word.

Tabel 1 Resultate vir die jaar tot 31 Desember 1980

\begin{tabular}{|c|c|c|c|c|c|c|c|c|}
\hline & & & $\begin{array}{r}\text { Voo } \\
+\end{array}$ & $\begin{array}{l}\text { dwins } \\
\text { EU }\end{array}$ & $\begin{array}{r}\text { Geen } v \\
+\end{array}$ & $\begin{array}{l}\text { aadwins } \\
\text { EU }\end{array}$ & $\begin{array}{r}\text { Voor } \\
+\end{array}$ & $\begin{array}{l}\text { dwins } \\
\text { EU }\end{array}$ \\
\hline & & & $\mathbf{A}$ & B & C & D & $\mathbf{E}$ & $F$ \\
\hline & D V & $\mathbf{K}$ & Wins & Kontant & Wins & Kontant & Wins & Kontant \\
\hline 1 & 33 & 1 & 61,46 & 3,16 & 42,59 & $(15,71)^{*}$ & 44,30 & 19,00 \\
\hline 2 & 23 & 1 & 61,46 & 15,26 & 42,59 & $(3,61)$ & 44,30 & 31,10 \\
\hline 3 & 13 & 1 & 61,46 & 27,36 & 42,59 & 8,49 & 44,30 & 43,20 \\
\hline 4 & -3 & 1 & 61,46 & 39,46 & 42,59 & 20,59 & 44,30 & 55,30 \\
\hline 5 & -2 & 1 & 55,74 & 44,74 & 43,16 & 32,16 & 44,30 & 55,30 \\
\hline 6 & -1 & 1 & 50,02 & 50,02 & 43,73 & 43,73 & 44,30 & 55,30 \\
\hline Aan & ntal & & & & & & & \\
\hline R37 & 7,44 & & 6 & 3 & 6 & 1 & 6 & 4 \\
\hline $\begin{array}{l}\text { Aan } \\
\text { R37 }\end{array}$ & ntal & & - & 3 & - & 5 & - & 2 \\
\hline
\end{tabular}


Gedurende prysstygings blyk dit dus dat die gaping tussen winste en kontantbewegings groter word. Dit wil voorkom dat 'n groot gaping mag dui op 'n klein verskansing teen inflasie en 'n klein gaping dui op 'n goeie verskansing. Sodra krediteure (K) groter is as debiteure (D) en voorraad (V), mag dit selfs wees dat die kontanttoename groter sal wees as die wins na belasting.

'n Verdere belangrike aspek is die groot positiewe uitwerking wat LIEU op kontantvloei het. Vir die meer voorraadintensiewe onderneming (bv. drie maande) is die kontanttoename $(F-B)=R 15,84$; vir twee maande se voorraad is die $R 10,56$, en vir een maand se voorraad is dit $R 5,28$. Vir 'n onderneming wat baie voorrade aanhou, sal 'n swaai na LIEU geweldige kontantvloeibesparings inhou, mits dit administratief moontlik is om LIEU toe te pas.

Daar is reeds daarop gewys dat in die afwesigheid van inflasie die kontant beskikbaar op 31 Desember 1980 R37,44 sou gewees het. Aanvaar dat dié bedrag net so jaarliks as dividende/delging van lenings, ens. benodig word. Enige kontantsyfer op 31 Desember 1980 wat laer is as $R 37,44$, kan dus beskou word- as 'kontantvloeiprobleme' van een of ander aard. Volgens hierdie arbitrêre definisie sal drie maatskappye van kolom $B$, vyf van kolom $D$ en twee van kolom $F$ kontantvloeiprobleme hê. Nodeloos om te sê dat die hoogs likiede maatskappye probleme ondervind en die minder likiedes beter vaar in hierdie eenvoudige voorbeeld waar die inflasiekoers van $11 \%$ groter is as die bruto-winsgrens van $10 \%$.

Die voorbeeld is doelbewus gekies om die argument te illustreer. In die algemeen is dit so dat hoe korter die siklus $\mathrm{D}+\mathrm{V}-\mathrm{K}$, hoe beter is die onderneming verskans teen inflasie. Andersom gestel, hoe swakker die likiditeit, hoe beter is ' $n$ onderneming verskans teen inflasie en hoe beter die likiditeit, hoe swakker verskans. Hierdie stelling geld egter nie algemeen nie, want hoe hoër die verhouding bruto-wins \%/inflasiekoers, hoe minder krities raak die likiditeit. Tewens, as die verhouding bruto-wins \%

inflasiekoers hoog is, maak dit eintlik nie veel saak of die onderneming baie of minder goed likied is nie.

Skematies is die hele aangeleentheid soos volg benader.

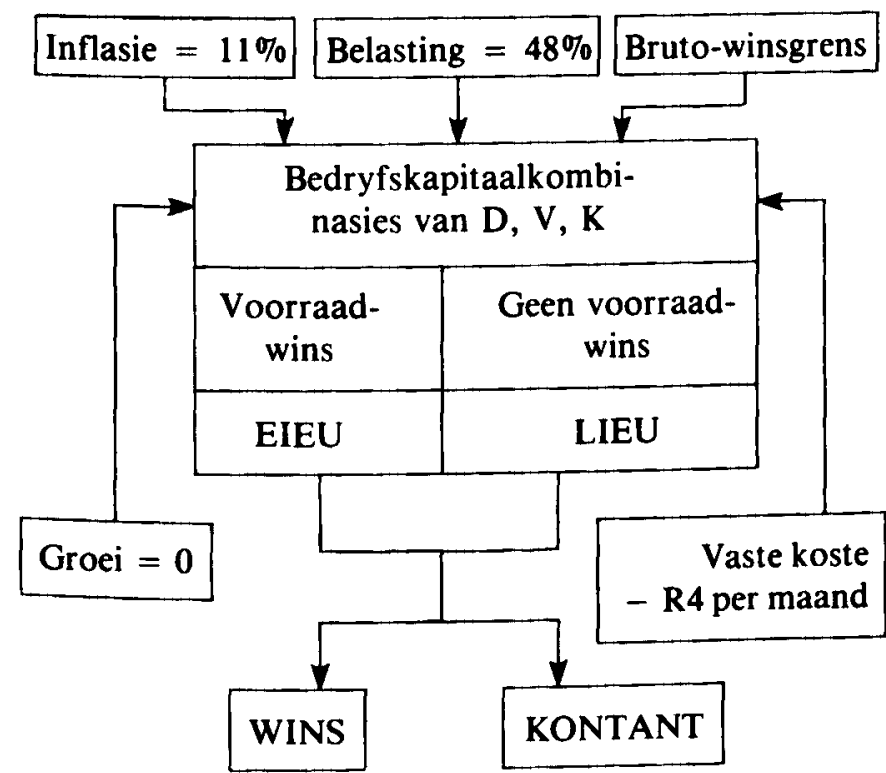

'n Rekenaarprogram (ontwikkel deur J.A. Victor van die Universiteit van Stellenbosch met behulp van 'n navorsingstoekenning van die Raad van Geesteswetenskaplike Navorsing) kan die volgende paramaters varieër:

0 inflasiekoerse

0 belastingkoerse

- bedryfskapitaalkombinasies

- vaste koste

- groei

- voorraadwins of geen voorraadwins

- EIEU of LIEU

Die probleem kan ook uit 'n ander oogpunt benader word naamlik om vas te stel wat die bruto-winsgrens moet wees om 'n bepaalde kontantbedrag van sê $R 37,44$ op 31 Desember 1980 te hê (kyk Tabel 2).

Die implikasies van Tabel 2 moet gemeet word teen die vorige bruto-winsgrens van $10 \%$. Wat kolom A betref, moet die eerste drie maatskappye hul bruto-winsgrense verhoog, en so ook vyf van kolom B en twee van kolom C. In geval 1 van kolom A word 'n nuwe winsgrens van $19,53 \%$ vir die hele 1980 benodig. Indien daar egter geslaag kan word om debiteure binne 60 dae te laat betaal in plaas van 90 dae, daal die benodigde bruto-winspersentasie van $19,53 \%$ na $14,71 \%$ wat dus neerkom op die aanbied van 'n kontantafslag van $4,82 \%$ vir 30 dae vroeër beţaal!

Tabel 2 Bruto-winspersentasie benodig sodat kontant op 31 Desember 1980 identies $(R 37,44)$ is aan wat dit sou gewees het sonder die $11 \%$ prysstyging op 1 Januarie 1980

\begin{tabular}{|c|c|c|c|c|c|c|}
\hline & D & V K & $\mathbf{K}$ & $\begin{array}{c}\text { Voorraadwins } \\
+ \text { EIEU } \\
(\%) \\
A\end{array}$ & $\begin{array}{c}\text { Geen } \\
\text { voorraadwins } \\
+ \text { EIEU } \\
(\%) \\
\text { B }\end{array}$ & $\begin{array}{c}\text { Voorraadwins } \\
+ \text { LIEU } \\
(\%) \\
\text { C }\end{array}$ \\
\hline 1 & 3 & 31 & 1 & 19,53 & 38,50 & 15,12 \\
\hline 2 & 2 & 31 & 1 & 14,71 & 23,80 & 11,35 \\
\hline 3 & 1 & 31 & 1 & 11,73 & 17,09 & 9,01 \\
\hline 4 & -3 & 31 & 1 & 9,71 & 13,24 & 7,42 \\
\hline 5 & -2 & 21 & 1 & 8,95 & 10,91 & 7,42 \\
\hline 6 & -1 & 11 & 1 & 8,18 & 9,01 & 7,42 \\
\hline
\end{tabular}

Aan die ander kant, indien onderneming 1 sou besluit om sy verkooppryse vir die eerste drie maande te hou op $R 1,10$, benodig hy ' $n$ verkoopprys van $R 1,54(1,11 \times$ $1,385)$ die orige nege maande. Indien hy egter volgens LIEU werk, benodig hy net $15,12 \%$. Dit dui weer eens op die baie groot uitwerking wat LIEU op kontantvloei het.

Die vraag ontstaan nou: hoe algemeen is bostaande stellings? Beteken dit dat slegs illikiede ondernemings verskans is teen inflasie en dat die tradisioneel sterk likiede ondernemings altyd sal swaar kry?

Om hierdie bewering te toets, is ' $n$ verdere eenvoudige geval geneem wat 'n herhaling is van die vorige behalwe dat:

o bruto-winsgrens $30 \%$ in plaas van $10 \%$ bedra;

o vaste koste $\mathrm{R} 24$ per maand is i.p.v. R4 per maand. 
Die verwagte wins (in die afwesigheid van prysstygings) bedra nog steeds $R 37,44$,

$12 \times[100 \times(1,30-1,00)-24]$

Minus Belasting $(0,48)$

Wins na belasting

Origens bly die hele voorbeeld identies aan die vorige. Weer eens styg die kosprys van $R 1,00$ na $R 1,11$ op 1 Januarie 1980 en mettertyd of dadelik word die verkooppryse verhoog na $R 1,11 \times 1,30=R 1,443$.

Die gevolg hiervan word in Tabel 3 geillustreer. Slegs voorraadwins + EIEU word as illustrasie gebruik en gerieflikheidshalwe word die detail van Tabel $1(10 \%$ winsgrens) weer gegee.

Die patroon by die hoër winsgrens $(30 \%)$ openbaar dieselfde neiging as die laer winsgrens $(10 \%)$. Weer eens is wins konstant vir die eerste vier ondernemings. Weer eens blyk dit dat die minder likiede (nr. 6) die hoogste kontantsyfer het, van R63,75, en die mees likiede (nr. 1) die laagste kontantsyfer het, van R10,29. Daar is tog 'n verskil tussen B en D. Dit blyk duidelik dat kolom B dwarsdeur hoër is as kolom D. Anders gestel, dit wil voorkom asof ons kan sê dat kolom B relatief beter verskans is as kolom D. Relatief tot $R 37,44$ is die negatiewe afwykings vanaf $R 37,44$ soveel kleiner en die positiewe af wykings soveel groter as in kolom D.

Dieselfde patroon word ook openbaar in Tabel 4 waar die $30 \%$ weer teenoor die $10 \%$ geplaas word in terme van gelykbreekpunt-persentasies.

Tabel 3 Resultate na 12 maande, dit wil sé, tot 31 Desember 1980 gebaseer op voorraadwins plus EIEU

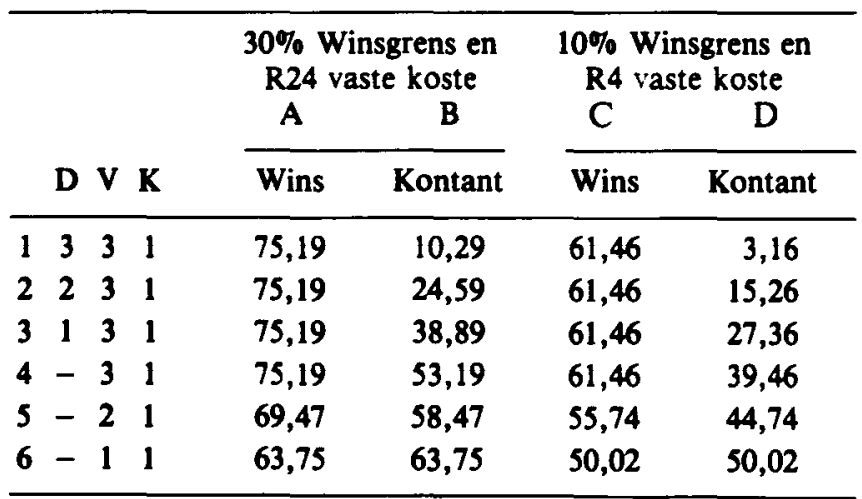

Tabel 4 Bruto-winspersentasies benodig sodat kontant op 31 Desember 1980 gelyk is aan R37,44 (slegs vir voorraadwins plus EIEU)

\begin{tabular}{cccccc}
\hline \multicolumn{2}{c}{ D } & V & K & $\begin{array}{c}30 \% \text { Winsgrens en } \\
\text { R24 vaste koste } \\
\text { A }\end{array}$ & $\begin{array}{c}10 \% \text { Winsgrens en } \\
\text { R4 vaste koste } \\
\text { B }\end{array}$ \\
\hline 1 & 3 & 3 & 1 & 37,55 & 19,53 \\
2 & 2 & 3 & 1 & 32,73 & 14,71 \\
3 & 1 & 3 & 1 & 29,75 & 11,73 \\
4 & - & 3 & 1 & 27,73 & 9,71 \\
5 & - & 2 & 1 & 26,96 & 8,95 \\
6 & - & 1 & 1 & 26,20 & 8,18 \\
\hline
\end{tabular}

Tabel 5 Relatiewe bruto-winsfaktore benodig sodat kontant op 31 Desember gelyk is aan R37,44

\begin{tabular}{cccccc}
\hline & & & $\begin{array}{c}30 \% \text { Winsgrens en } \\
\text { R24 vaste koste } \\
\text { D }\end{array}$ & K & $\begin{array}{c}10 \% \text { Winsgrens en } \\
\text { R4 vaste koste } \\
\text { B }\end{array}$ \\
\hline 1 & 3 & 3 & 1 & $1,25^{*}$ & $1,95^{* *}$ \\
2 & 2 & 3 & 1 & 1,09 & 1,47 \\
3 & 1 & 3 & 1 & 0,99 & 1,17 \\
4 & - & 3 & 1 & 0,92 & 0,97 \\
5 & - & 2 & 1 & 0,90 & 0,89 \\
6 & - & 1 & 1 & 0,87 & 0,82 \\
\hline
\end{tabular}

$* 37,55 \div 30=1,25 . \quad * 19,53 \div 10=1,95$.

Indien kolom $\mathrm{A}$ uitgedruk word as 'n desimaal van $30 \%$ en $B$ uitgedruk word as 'n desimaal van $10 \%$, verkry ons Tabel 5.

Die variasie in kolom B is baie groter as in kolom $\mathbf{A}$. Die algemene gevolgtrekking sou dus gemaak kan word dat die relatief illikiede maatskappy altyd die grootste kontant gaan hê tydens prysstygings (Tabel 3, onderneming 6) maar dat die relatiewe verskil tussen die minder likiede (Tabel 5 , onderneming 6) en die meer likiede (Tabel 5 , onderneming 1) krimp soos duidelik blyk uit die klein verskil in kolom $A(1,25-0,87)$ teenoor die groter verskil in kolom $B(1,95-0,82)$.

As algemene gevolgtrekking kan die stelling gemaak word dat tydens inflasie daar skerp gelet moet word op die siklus $\mathrm{D}+\mathrm{V}-\mathrm{K}$ veral as die bruto-winsgrens laag is in verhouding tot die verwagte inflasiekoers. Raak die wins-grens nou hoër in verhouding tot dieselfde inflasiekoers, raak die siklus $D+V-K$ minder belangrik. Sodra die nuwe winsgrens nader beweeg aan die ou winsgrens (nader beweeg aan 1, in Tabel 5), beteken dit dat daardie onderneming meer verskans raak teen inflasie. Met ' $n$ verhoging in bruto-wins word daar tewens ' $n$ posisie bereik waar die $D+V-K$ glad nie saak maak nie.

Die nut van hierdie sensitiwiteitstudie is dus om vas te stel watter inflasiekoers krities gaan wees vir 'n bepaalde onderneming met:

- 'n bepaalde bedryfskapitaalsamestelling;

- 'n bepaalde bruto-winsgrens.

So mag dit wees dat 'n onderneming heel goed geplaas is solank as die inflasiekoers sê laer as $12 \%$ per jaar is. Styg dit daarbo, kan daar baie probleme ontstaan.

Aan die ander kant verskaf dit ook aan bestuur 'n antwoord op bestuursbeslissings soos, wat gebeur as:

- debiteure met sê een maand verlaag/verhoog

- voorraad met sê een maand verlaag/verhoog

- krediteure met sê een maand verlaag/verhoog

o winsgrense verander

- groei in ag geneem word

- geswaai word van 'n beleid van voorraadwins na een van geen voorraadwins (of andersom)

- geswaai word vanaf EIEU na LIEU (of andersom).

Kortom word die model gesien as 'n nuttige hulpmiddel vir die vasstelling van 'n redelike winsgrens gegewe die werklikheid van veranderende pryspeile. 


\section{Summary}

Since the advent of double-digit inflation, frequent warnings have been sounded against the adverse impact of inflation on an enterprise's cash flow. It is generally implied that inflation has only negative cash flow impacts and the question therefore arises whether this is indeed the case or whether positive cash flow impacts might be experienced in certain circumstances.

Analysis of a typical trading concern was performed to determine the circumstances, if any, in which the cash flow of such a concern would be adequately hedged against inflation. The analysis, which focused on the interrelationship between the rate of inflation, the gross margin and the composition of net working capital, considered situations with and without inflation-based inven- tory profits under both FIFO and LIFO inventory systems. The individual and combined influences of the various components of net working capital are readily identifiable in the analysis.

A very significant result of the analysis is that illiquidity - a low level of net working capital - is a prerequisite for a hedge against inflation if an enterprise's gross margin is low relative to the rate of inflation. The illiquidity requirements becomes more/less critical as the ratio of gross margin to inflation rate deteriorates/improves. With high gross margins, the liquidity level becomes relatively unimportant. In essence, then, high inflation rates call for high gross margins or, for enterprises then faced with low margins, careful management of working capital levels. 